\title{
Pharmacognostic and Preliminary Phytochemical Investigation of stem of Conocarpus lancifolius
}

\author{
Research Article
}

\section{Disha P Prajapati ${ }^{*}$, Tanvi R Dodiya ${ }^{2}$}

\author{
1. Assistant Professor, 2. Associate Professor, \\ Department of Pharmacognosy, Parul Institute of Pharmacy \& Research, Parul University, Vadodara, Gujarat.
}

\begin{abstract}
Aims: To evaluate pharmacognostic and preliminary phytochemical analysis of stem of Conocarpus lancifolius including macroscopic, microscopic and physicochemical parameters. Methods and Material: Macroscopic and microscopic properties of dried stem were investigated. Preliminary phytochemical analysis of various extracts and fluorescence analysis of dried stem powder was performed using various chemicals. Physicochemical parameters were evaluated as per WHO guidelines. Results: Organoleptic parameters of stem of $C$. lancifolius like colour, shape, size etc were noted. Transverse section of fresh stem revealed the presence of epidermis, cortex, sone cells, phloem, xylem and pith. Whereas, powder microscopy showed the presence of epidermis, xylem, stone cells, phloem fibre with crystals of calcium oxalate etc. Phytochemical screening of methanolic extract of stem showed presence of alkaloids, flavonoids, glycoside, steroids etc. Ethyl acetate extract showed the presence of alkaloids and steroids while aqueous extract showed presence of tannins. Physicochemical parameters viz. ash value, extractive value, moisture content, fluorescence analysis and foaming index of stem powder were determined. The total tannins were also determined in the stem of $C$. lancifolius. Conclusion: The present study revealed pharmacognostic and preliminary phytochemical parameters of stem of C. lancifolius which would be beneficial for its standardization and future scope of the work.
\end{abstract}

Key Words: Conocarpus lancifolius, Combretaceae, Pharmacognostic, Physicochemical, Standardization.

\section{Introduction}

In then recent years there is a renovated interest in drugs of natural origin because of their safety as well as there are incidences of harmful nature of the synthetic drugs (1). Pharmacognostic study deals with the authentication and quality assessments of crude drugs and herbal materials based on various macroscopic, microscopic, physicochemical and chemical characteristics (2). Unexplored drug resources in medicinal plants have great therapeutic potential as they are helpful in achieving new drugs with lead targets and unique mechanism of action (3).

Conocarpus lancifolius belonging to Combretaceae family is an evergreen tree usually growing $10-20 \mathrm{~m}$ tall. The tree is harvested from the wild for local use as a medicine and a source of good quality wood and fuel (4). The tree is found beside intermittent watercourses of Northern Somalia and in the southwest part of the Arabian Peninsula in Djibouti, Sudan, Kenya, north and south Yemen and Pakistan (5).

\section{* Corresponding Author:}

Disha P Prajapati

Assistant Professor, Department of Pharmacognosy, Parul Institute of Pharmacy \& Research,

Parul University, Vadodara,

Gujarat. India

Email Id: disha.prajapati@paruluniversity.ac.in
It is a heat tolerant plant and has potential use in the phytoremediation of polluted soil (6). One of the studies revealed that $C$. lancifolius tree was able to uptake high levels of chromium, vanadium and nickel and accumulate them in the tree's roots. Furthermore, it tolerated high concentration of several metals like aluminum, calcium and iron in all plant tissues (7).

A gum exudated from the tree is used to treat chest and bowel complaints traditionally. The wood being durable in water is used for ship building and it also offers good fuel and high quality of charcoal (8). The various extract like dichloromethane, methanol and aqueous exhibited varying but potent antioxidant, phytotoxic and anti-urease activities (3). The alkaloidal extract, silver nanoparticles, phenols and aqueous extract showed antibacterial and antifungal activity in various pathogenic strains $(9,10,11)$.

The alcoholic and methanolic extract showed the antidiabetic potential due to gluconeogenesis suppression in alloxan induced diabetic rabbits (12). The alcoholic extract showed substantial amount of bioactive ingredients which are rich source of high value metabolite of functional nature which supports its use as nutraceuticals (13). C.lancifolius extract and lancifoliate possess potent cytotoxic and antifungal properties (14).

The methanolic extract yielded two compounds: 2,3,8- tri-O-methyl ellagic acid and 3-O- methyl ellagic acid 4-O- $\beta$-D- glucopyranoside (15). The fruits of the plant showed the presence of trimethoxy ellagic acid 
Disha P Prajapati et.al., Pharmacognostic and Preliminary Phytochemical Investigation of stem of Conocarpus lancifolius

derivative, kaempferol 3-O- rutinoside 2 and $\alpha$ sitosterol glucoside 3 which showed anti-inflammatory, cytotoxic and PPAR agonistic activities (16). Alcoholic extract of C.lancifolius showed synergistic effect with Mentha spicata against S.pyrogens causing dental caries and infection of gums and mouth (17).

\section{Materials and methods}

\section{Collection and authentication of plant material}

Fresh stem of Conocarpus lancifolius was collected from the campus of Parul University, Vadodara. Plant was authenticated at Parul Institute of Applied Sciences. The stems were dried under shade and then it was powdered and passed through sieve 60\# and then stored in airtight container for further investigation.

\section{Macroscopy}

Various organoleptic and macroscopical characteristics like colour, odour, taste, size and shape of the plant material were recorded.

\section{Microscopy}

For qualitative microscopy the freehand transverse section of fresh sample of the stem of $C$. lancifolius were taken using razor blade. Lignified, cellulosic and other identifying features were studied by staining with phloroglucinol in concentrated $\mathrm{HCl}$ and iodine. The slides were observed under microscope in various magnification and photographs were recorded using camera.

\section{Powder microscopy}

Dried powder of the stem of plant material on slide was cleared with chloral hydrate solution and then stained with phloroglucinol in concentrated $\mathrm{HCl}$. The slides were observed under the microscope in various magnification and photographs were recorded using camera (18).

\section{Phytochemical investigation}

The phytochemical investigation of the dried powder material was done by extracting $100 \mathrm{gm}$ of powder with organic solvents in increasing polarity from petroleum ether, chloroform, ethyl acetate, methanol and water using Soxhlet apparatus. The extracts were dried and the percentage yield and characteristics of the extract were reported. Further the extracts were subjected to various qualitative phytochemical test for the presence of various phytoconstituents like alkaloids, glycosides, tannins, flavonoids, saponins, sterols, etc. according to the reported methods $(18,19)$.

\section{Physicochemical analysis}

The plant material was subjected to various physicochemical parameters like ash value, extractive value, loss on drying, foaming index, etc. according to the WHO guidelines $(20,21)$.

\section{Determination of total tannin}

About 2gm of powdered sample was extracted for $20 \mathrm{hrs}$ with Petroleum ether. The residue was boiled for $2 \mathrm{hrs}$ with $300 \mathrm{ml}$ of double distilled water. The solution was cooled and diluted up to $500 \mathrm{ml}$ and filter. From filtrate, $25 \mathrm{ml}$ of infusion was taken into conical flask and $20 \mathrm{ml}$ indigo carmine solution was added and diluted with $750 \mathrm{ml}$ of double distilled water. Then the solution was titrated with standard $\mathrm{KMnO}_{4}$ solution, $1 \mathrm{ml}$ at a time until blue color changed to green. Then few drops were added at a time till solution became golden yellow in color. Similarly, the blank reading was taken by omitting the sample $(22,23)$.

\section{Fluorescence analysis}

The powdered plant material was treated with different reagents like water, picric acid, concentrated hydrochloric acid, concentrated sulphuric acid, concentrated nitric acid, glacial acetic acid, iodine solution, ferric chloride, etc. Then the powder color was reported by observing in daylight and UV light at 366 $\mathrm{nm}$ and $254 \mathrm{~nm}(24)$.

\section{Results}

\section{Macroscopy of stem of Conocarpus lancifolius}

Macroscopically the Conocarpus lancifolius is an evergreen tree which grows to the height of $20 \mathrm{~m}$ and $60-250 \mathrm{~cm}$ or more in diameter. The bark is thick and has grey to brown color. The twigs are brittle and pentagonal in shape and having greenish color. The arrangement of twigs on the stem is alternate. The arrangement of leaves on the stem is alternate and at each node the single leaf is found on the twig. The surface of the stem is pubescent and shows smooth powdery fracture.

\section{Figure 1 Stem of Conocarpus lancifolius}

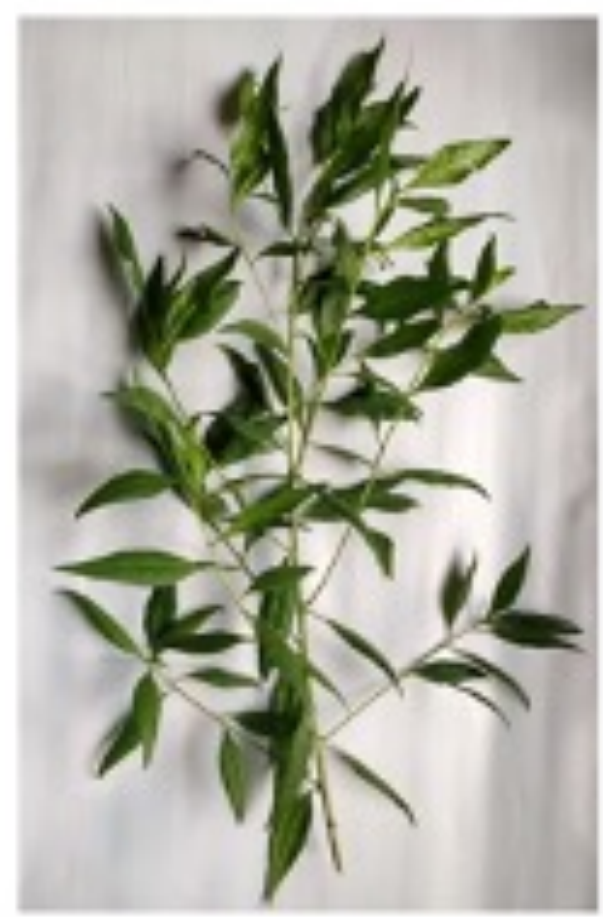


Microscopy of stem of Conocarpus lancifolius

The transverse section of the stem shows epidermis made up of 10-12 layers of tangentially elongated parenchyma cells. Cortex is made up of several layers of thin walled polyhedral parenchymatous cells with intercellular spaces. Some parenchymatous cells in the cortex are found to be opalescent when stained with iodine solution. The xylem occupies the one third portion of the transverse section. The xylem is cut transversely by rows of medullary rays whose cells are lignified. Because of lignification, it is difficult to differentiate medullary rays from other wood elements in the section. Xylem consists of vessels and lignified wood parenchyma. The vessels which are relatively wide show pitted borders. The pith consists of the 2-3 layers of spongy parenchymatous cells. (Figure 2)

\section{Figure 2 Microscopical characteristics of stem of Conocarpus lancifolius}
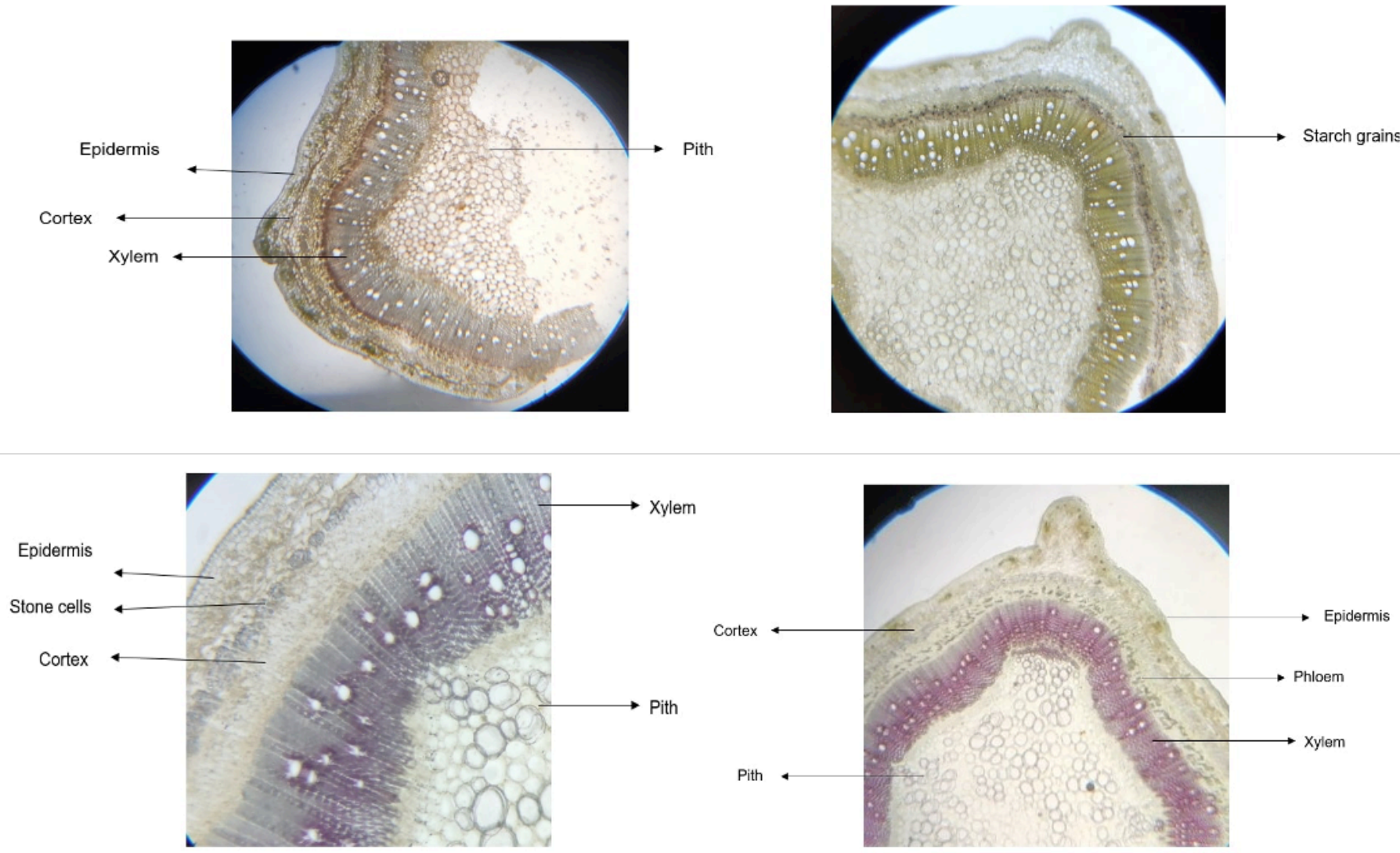

\section{Powder microscopy of stem of Conocarpus lancifolius}

The powder microscopy of the stem showed the presence of phloem fibres, epidermal cells, stone cells and pitted xylem vessels (Figure 3).

\section{Figure 3 Powder microscopical characteristics of stem of Conocarpus lancifolius}

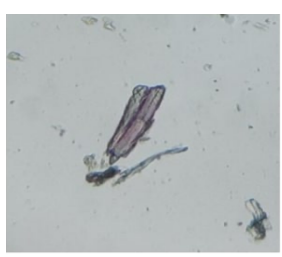

$\underset{\text { vessel }}{\text { Lignified }}$ ylem

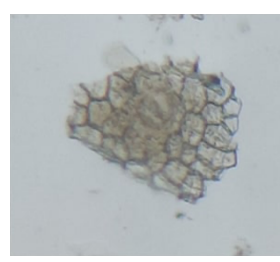

Epidermis

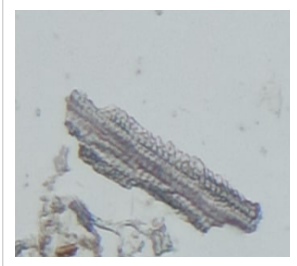

Xylem vessels

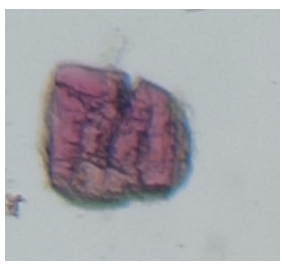

Stone cells

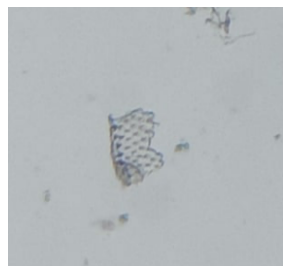

Pitted xylem vessels

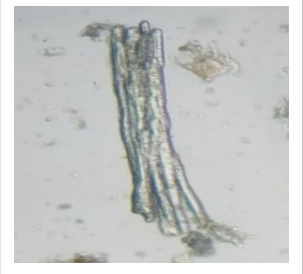

Phloem fibers

\section{Phytochemical Investigation}

The successive solvent extraction of the C. lancifolius stem powder in various solvents was done and its percentage yield, color and consistency are reported in the Table 1 . The phytochemical analysis of the various extracts of the stem was performed for the presence of various phytoconstituents in the plant. The results of the qualitative chemical tests are reported in Table 2. 
Disha P Prajapati et.al., Pharmacognostic and Preliminary Phytochemical Investigation of stem of Conocarpus lancifolius

Table 1: Characteristics of Extracts of Stem of Conocarpus lancifolius

\begin{tabular}{|r|l|l|l|l|}
\hline Sr. No. & Name of extract & Colour & Consistency & \multicolumn{1}{c|}{ Yield } \\
\hline 1 & Petroleum ether & Light green & Sticky & $2 \% \mathrm{w} / \mathrm{w}$ \\
\hline 2 & Chloroform & Brown & Dry & $1 \% \mathrm{w} / \mathrm{w}$ \\
\hline 3 & Ethyl acetate & Brown & Slightly sticky & $1 \% \mathrm{~W} / \mathrm{w}$ \\
\hline 4 & Methanol & Brown & Dry & $11 \% \mathrm{~W} / \mathrm{w}$ \\
\hline 5 & Water & Dark brown & Dry & $2 \% \mathrm{w} / \mathrm{w}$ \\
\hline
\end{tabular}

Table 2: Phytochemical analysis of various extract of stem of Conocarpus lancifolius

\begin{tabular}{|c|c|c|c|c|c|c|}
\hline Chemical constituents & Chemical test & Petroleum ether & Chloroform & Ethyl acetate & Methanol & Water \\
\hline \multirow[t]{5}{*}{ Alkaloids } & Dragendorff's test & - & - & + & + & - \\
\hline & Mayer's test & - & - & + & + & - \\
\hline & Hager's test & - & - & + & + & - \\
\hline & Wagner's test & - & - & + & + & - \\
\hline & Tannic acid test & - & - & + & + & - \\
\hline Glycosides & General test & - & - & - & - & - \\
\hline \multirow[t]{2}{*}{ Steroids } & Salkowski test & + & + & + & + & - \\
\hline & Lieberman-burchard test & + & + & + & + & - \\
\hline \multirow[t]{2}{*}{ Flavonoids } & Shinoda & - & - & - & + & - \\
\hline & Sulphuric acid test & - & - & - & + & - \\
\hline \multirow[t]{2}{*}{ Protein } & Biuret test & - & - & - & + & - \\
\hline & Millon's test & - & - & - & + & - \\
\hline Amino acid & Ninhydrin test & - & - & - & + & - \\
\hline \multirow[t]{3}{*}{ Tannins } & Ferric chloride test & - & - & - & + & + \\
\hline & Gelatin test & - & - & - & + & + \\
\hline & Lead acetate test & - & - & - & + & + \\
\hline
\end{tabular}

*+ Present , - Absent

\section{Physicochemical analysis}

The various physicochemical parameters like ash value, extractive value, moisture content and foaming index are important parameters for identification and detection of adulteration in the powder sample. The results of the same are stated in Table 3.

Table 3: Physicochemical parameters of stem of Conocarpus lancifolius

\begin{tabular}{|c|l|c|}
\hline Sr. No & \multicolumn{1}{|c|}{ Parameters } & Value \\
\hline 1 & Water soluble extractive value & $40 \%$ \\
\hline 2 & Alcohol soluble extractive value & $20 \%$ \\
\hline 3 & Total ash value & $2.75 \%$ \\
\hline 4 & Acid insoluble ash value & $0.9 \%$ \\
\hline 5 & Water soluble ash value & $1.9 \%$ \\
\hline 7 & Moisture content & $10 \%$ \\
\hline
\end{tabular}

Total tannins

Stem of C. lancifolius contains $3.741 \%$ of total tannin.

\section{Fluorescence analysis}

The fluorescence analysis of the powder with various reagents is reported in the Table 4 .

Table 4: Fluorescence analysis of stem of Conocarpus lancifolius

\begin{tabular}{|c|l|l|l|l|}
\hline Sr. No. & \multicolumn{1}{|c|}{ Reagents } & Visible & UV short (254 nm) & UV long (365 nm) \\
\hline 1 & Powder & Buff & Buff & Brown \\
\hline 2 & Conc. Nitric acid & Brown & Greenish brown & Dark brown \\
\hline 3 & Conc. HCl & Brown & Greenish brown & Dark brown \\
\hline 4 & Conc. Sulphuric acid & Blackish brown & Blackish brown & Black \\
\hline 5 & Ammonia & Dark brown & Greenish brown & Black \\
\hline 6 & $10 \%$ Ferric chloride & Greenish black & Greenish black & Black \\
\hline 7 & Glacial acetic acid & Brown & brown & Dark brown \\
\hline 8 & Iodine & Brown & Greenish brown & Black \\
\hline 9 & Picric acid & Yellowish brown & Greenish yellow & Dark brown \\
\hline 10 & Dil. Sodium hydroxide & Brown & Greenish brown & Dark brown \\
\hline
\end{tabular}




\section{Discussion}

According to WHO guidelines the morphology and microscopy are the important parameters for the evaluation of the crude drugs. They are cost effective, reliable and timesaving methods for the identification and authentication of the plant materials (25).

The phytochemical analysis of the various extracts of the stem showed the presence of various phytoconstituents which are responsible for the pharmacological activity of the plant. The ethyl acetate and methanol extract showed the presence of alkaloids and tannins. The steroids were found in the petroleum ether, chloroform, ethyl acetate, methanol and aqueous extract. The flavonoids, proteins and amino acids were found in the methanolic extract. The moisture content is directly responsible for the microbial contamination which leads to the deterioration of the plant material. The ash value is determined in three forms total ash, acid insoluble ash and water-soluble ash which gives the idea about the quality of the drugs and indicates presence of inorganic constituents like carbonates, phosphates and silicates calcium, magnesium, sodium and potassium. The extractive value gives the idea about the presence of various phytoconstituents and also helps to estimate the solubility of the particular component in a respective solvent.

The present study was planned to focus on establishing the pharmacognostic standard, authentication and identification of the stem of Conocarpus lancifloius. This information may be further useful in the preparation of the monograph of the plant.

\section{Acknowledgement}

The authors are grateful to the authorities of Parul Institute of Pharmacy \& Research, Parul University, Vadodara, Gujarat for the facilities.

\section{Conflict of interest}

The authors declare no conflict of interest.

\section{References}

1. Chanda S. Importance of pharmacognostic study of medicinal plants: An overview. Journal of pharmacognosy and phytochemistry. 2014 Jan $1 ; 2(5)$.

2. Trivedi A, Neeraj Sethiya K, Mishra SH. Preliminary pharmacognostic and phytochemical analysis of "Granthika" (Leonotis nepetaefolia): An Ayurvedic herb.

3. Saadullah M, Chaudary BA, Uzair M. Antioxidant, phytotoxic and antiurease activities, and total phenolic and flavonoid contents of Conocarpus lancifolius (Combretaceae). Tropical Journal of Pharmaceutical Research. 2016 Apr 8;15(3):555-61.

4. Fern K. Tropical Plants Database. (Cited 2018 December 18). Available from: tropical. The ferns. info/view tropical. php.
5. Little Jr EL. Common fuelwood crops. A handbook for their identification. Common fuelwood crops. A handbook for their identification. 1983.

6. Redha A, Al-Hasan R, Jose J, Saju D, Afzal M. The photosynthetic apparatus of Conocarpus lancifolius engl. (Combretaceae) suffers damage in soil contaminated with heavy metals. Botany. 2019;97(3):179-89.

7. Al-Surrayai T, Yateem A, Al-Kandari R, et.al. The use of Conocarpus lancifolius trees for the remediation of oil-contaminated soils. Soil \& Sediment Contamination. 2009 Apr 24;18(3):354-68.

8. Moran RC, Smith AR. Phytogeographic relationships between neotropical and AfricanMadagascan pteridophytes. Brittonia. 2001 Apr;53(2):304-51.

9. Ali HM, Salem MZ, Abdel-Megeed A. In-vitro antibacterial activities of alkaloids extract from leaves of Conocarpus lancifolius engl. J. Pure Appl. Microbiol. 2013 Sep 1;7(3):1903-7.

10. Raheema RH, Shoker RM. Phytochemicals screening and antibacterial activity of silver nanoparticles, phenols and alkaloids extracts of Conocarpus lancifolius. Eur Asian Journal of BioSciences. 2020 Oct 31;14(2):4829-35.

11. Touqeer S, Saeed MA, Ansari F, et.al. Antibacterial and antifungal activity of Conocarpus lancifolius engl. (Combretaceae).

12. Saadullah M, Chaudary BA, Uzair M, Afzal K. Anti-diabetic potential of Conocarpus lancifolius. Bangladesh Journal of Pharmacology. 2014 Jun 7;9(2):244-9.

13. Raza SA, Chaudhary AR, Mumtaz MW, et.al. Metabolite profiling and antidiabetic attributes of ultrasonicated leaf extracts of Conocarpus lancifolius. Asian Pacific Journal of Tropical Biomedicine. 2020 Aug 1;10(8):353.

14. Saadullah M, Asif M, Yaseen HS, et.al. Isolation, Characterization and Preliminary Cytotoxic and Antifungal Evaluations of Novel Lancifoliate Isolated from Methanol Extract of Conocarpus lancifolius. Anti-Cancer Agents in Medicinal Chemistry (Formerly Current Medicinal ChemistryAnti-Cancer Agents). 2020 Sep 1;20(14):1664-72.

15. Saadullah M, Asif M, Sattar A, et.al. Wajid M, Rasool A, Uzair M, Afzal S. Cytotoxic and antioxidant potentials of ellagic acid derivatives from Conocarpus lancifolius (Combretaceae). Tropical Journal of Pharmaceutical Research. 2020 Jun 29;19(5):1037-80.

16. Al-Taweel AM, Perveen S, Fawzy GA, et.al . New ellagic acid derivative from the fruits of heattolerant plant Conocarpus lancifolius engl, and their anti-inflammatory, cytotoxic, PPAR agonistic activities. Pakistan journal of pharmaceutical sciences. 2016 Sep 2;29.

17. Jassim JN, Mahmood MS. Synergistic effect of alcohol extract of Mentha spicata and Conocarpus lancifolius against bacteria causing dental caries and some infections of gums and mouth. Plant Archives. 2020;20(1):2623-5. 
18. Khandelwal K. Practical pharmacognosy. Pragati Books Pvt. Ltd.; 2008 Sep 7.

19. Brain KR, Turner TD. The practical evaluation of phytopharmaceuticals. Bristol: WrightScientechnica; 1975.

20. World Health Organization. General guidelines for methodologies on research and evaluation of traditional medicine. World Health Organization; 2000 .

21. Katayama K, Yamaguchi R, Imoto S, et.al. Analysis of questionnaire for traditional medicine and development of decision support system. Evidence-
Based Complementary and Alternative Medicine. 2014 Jan 1;2014.

22. World Health Organization. The international pharmacopoeia. World Health Organization; 2006.

23. Sutar M, Malvankar K, Singh S. Pharmacognostical and phytochemical investigation of leaves of a weed Tridax procumbens L. International Journal of Current Pharmaceutical Research. 2013;5(1):29-33.

24. Yazdinezhad A, Ramezanloo N, Mozaffari S. Pharmacognostic and phytochemical investigation of Heracleum persicum Desf. ex Fischer. 